East African Medical Journal Vol. 85 No. 11 November 2008

EFFECT OF SEASONAL RAINFALL AND OTHER ENVIRONMENTAL CHANGES, ON SNAIL DENSITY AND INFECTION RATES WITH SCHISTOSOMA MANSONI FIFTEEN YEARS AFTER THE LAST SNAILS' STUDY IN KIGUNGU, ENTEBBE, UGANDA

E. I. Odongo-Aginya, PhD, Principal Research Officer, Uganda Virus Research Institute, P. O. Box 42, Entebbe, Uganda, F. K. Kironde, PhD, Associate Professor, Department of Biochemistry, Makerere University, P. O. Box 7062 Kampala, Uganda, N.B. Kabatereine, PhD, Senior Entomologist, Vector Control Department Wandegeya, P. O. Box 1661 Kampala, Uganda, P. Kategere, Diploma Medical Laboratory Technology, Medical Laboratory Technician, Uganda Virus Institute P. O. Box 42 Entebbe, Uganda and F. Kazibwe, PhD, Senior Entomologist, Vector Control Department Wandegeya, P. O. Box 1661, Kampala, Uganda

Request for reprints to: Dr. E. I. Odongo-Aginya, Uganda Virus Research Institute, P. O. Box 42, Entebbe, Uganda

\title{
EFFECT OF SEASONAL RAINFALL AND OTHER ENVIRONMENTAL CHANGES, ON SNAIL DENSITY AND INFECTION RATES WITH SCHISTOSOMA MANSONI FIFTEEN YEARS AFTER THE LAST SNAILS' STUDY IN KIGUNGU, ENTEBBE, UGANDA
}

\author{
E. I. ODONGO-AGINYA, F. K. KIRONDE, N. B. KABATEREINE, P. KATEGERE and F. KAZIBWE
}

\begin{abstract}
Background: The last study on snail population density in relation to rainfall pattern in Kigungu canoe landing and recreational sites on Lake Victoria shore was earlier carried out about fifteen years ago. This study also reviewed the influence of other environmental factors on the snails' infection rate.

Objective: To reassess the density dynamic of Biomphalaria (B) choanomphala and Biomphalaria (B) pfeifferi, which act as the intermediate host for $S$. mansoni and Bulinus (B) globosus, and Bulinus (B) tropicus, which act as intermediate host for $S$. haematobium.

Design: Retrospective study.

Setting: Busy canoe landing sites along Lake Victoria in Kigungu fishing village were selected for the snail sampling.

Results: Nine thousand one hundred and ninety four B. choanomphala were collected over the study period. The numbers of $B$. choanomphala collected in each year was 4742 $(51.6 \%)$ and $4452(48.4 \%)$ in 2004 and 2005 respectively. Of the 4742 B.Choanomphala collected in 2004, $82(1.7 \%)$ shed human cercariae and $329(6.7 \%)$ shed non-human cercariae. Whereas in 2005, out of 4452 B. choanomphala collected $302(6.85 \%)$ shed non-human cercariae and $82(1.8 \%)$ shed human cercariae. Similarly, 4173 B. pfeifferi were also collected in the same period. Out of which $2224(53.3 \%)$ were collected in 2004 and $1949(46.7 \%)$ in 2005. For B. pfeifferi, 42 (1.9\%) out of 2224 snails collected in 2004 shed human cercariae and $246(11.1 \%)$ shed non-human cercariae. While in 2005, 33 out of 1949 snails $(1.7 \%)$ shed human cercariae and $159(8.2 \%)$ shed non-human cercariae. Other snails of medical importance collected included 292 B. globosus and 3094 B. tropicus. None of the Bulinus spp. collected shed any human cercariae but $37(2.1 \%)$ and $30(2.3 \%)$ B. tropicus shed non-human cercariae in 2004 and 2005 respectively. In 2004 and 2005, the area received, $1729 \mathrm{~mm}$ and $1959 \mathrm{~mm}$ of rainfall respectively. The mean rainfall during the year was $144.05 \mathrm{~mm}$ and $163.3 \mathrm{~mm}$ in 2004 and 2005 respectively. There was a negative correlation between rainfalls and snail density dynamic.

Conclusion: We have found in this study that in spite of the bush clearing of the papyrus swamps which originally was the major habitats for B. choanomphala, $B$. pfeifferi and the Bulinus spp the intermediate host for schistosome at all canoe landing sites at Kigungu, these snails are still present. Moreover, that their population density dynamic and infection rate are inversely proportional to the rainfall pattern.
\end{abstract}




\section{INTRODUCTION}

All intermediate hosts for schistosome species are fresh water snails and each genus acts as a host for specific schistosome species. Biomphalaria and Bulinus are the two important genera for human and bovine schistosome in Africa and South America countries $(1,2)$. Biomphalaria species are intermediate hosts for S. mansoni, while Bulinus species are intermediate hosts for S. haematohium and S. intercalatum (3). In Asian countries including Japan, Oncomelania is the intermediate host for $S$. japonicum $(4,5)$. These snails are hermaphroditic although most species are capable of self-fertilisation (6). Egg masses are deposited underneath submerged vegetations and floating objects. The incubation period of egg masses are determined by the ambient temperature. Hatching is accomplished between 30 to 40 days at a temperature range of about $0-20^{\circ} \mathrm{C}(7)$. Similarly their growthis also temperature dependent with favourable temperature ranging from $18-30^{\circ} \mathrm{C}$. Their soft bodies are covered with hard protective shells (5). Biomphalaria and Bulinus species can be found in localised foci in water bodies such as ponds, lakes shores and river banks, The chemical composition of water and rainfall in an area are some of the major factors that affect snail distribution and density at transmission sites $(1,8)$. Furthermore, snail population density and their infection rates are seasonal and are greatly influenced by rainfall and ambient temperature (8). Odongo-Aginya et al. (12) showed that B. pfeifferi was commonly found in papyrus swamp along the lakeshore sites. While $B$. choanomphala was found on rocks and sandy beaches, B. tropicus and B. globosus were mainly found on rocky and sandy areas. Other snails of no medical importance which were found in Kigungu landing sites included Pila ovata, Melanoides tubaculata, Lymnae natalensis and Bellamya SPP (8).

Sincethen therehavebeen environmentalmodification along all canoe landing and recreational sites in Kigungu. The papyrus swamps and sedges along the lakeshore, which used to provide suitable habitats for B. pfeifferi, B. sudanica and the Bulinus spp. have been cleared and replaced by sandy beaches. Currently, these opened areas are where the residents do most of their domestic and recreational activities. Furthermore, sections of these beaches serve as canoe landing sites for food vendors, charcoal and firewood dealers. Permanent and semi-permanent settlements have been built in some parts as close as ten metres away from the shoreline. These owners of these settlements have erected cement concrete slaps at the lake side to serve as sand brake to the homes denying good habitats for the snails. In addition these homes have in-built flash toilets which the families use. Beside Entebbe municipal council under the programme of provision of safe water to rural areas has drilled boreholes and installed communal tap water pipes in most of the areas around these canoe landing sites to reduce the frequent contact with the schistosome infested water. In addition to these, as part of health education to reduce contamination of the lakeshore with their excreta the community is encouraged to build pit latrines and use them. These types of environmental changes have been known to influence the distribution patterns and the population dynamics of the snails in permanent water bodies (5). It is interesting to note that all the residents in these homes have knowledge about schistosomiasis (popularly known to them as Bilazia) butwereignorant about the intermediate hosts for neither S. mansoni nor the mode of transmission. They believed that schistosomiasis is transmitted by drinking unboiled lake water. During the survey, the residents were shown the specimens of intermediate hosts and the mode of S. mansoni transmission using the life cycle charts of both S. mansoni and S. haematobium. Such knowledge is essential for those who live in endemic areas for regular monitoring of intermediate hosts in water contact sites (10).

After the last study which was carried out on the snail distribution and transmission of schistosomiasis mansoni in Kigungu fishing village in 1987 (8), there have been a number of environmental changes in Kigungu village which started about 1994 at all the canoe landing sites. These categories of environmental changes have been observed to have effect on snails dynamic at schistosome transmission sites (9).

Therefore the aim of this study was to revisit and examine possible effect of seasonal distributions of intermediate hosts along Lake Victoria shores at Kigungu village and transmission potential based on environmental changes along these lake shores fifteen years after the last snails' study in 1987 (8).

\section{MATERIALS AND METHODS}

This study was conducted in Kigungu fishing village, which is situated along Lake Victoria in Entebbe peninsula. The village is located at the extreme south-western end of Entebbe peninsula, at latitude ${ }^{4} 35$ to ${ }^{4} 38$ East and ${ }^{\circ} 03$ to ${ }^{\circ} 07$ north. It is about ten kilometres south of Entebbe municipality next to Entebbe International Airport (Figures 1 and 2). 


\section{Figure 1}

Map of Entebbe peninsula showing location of Kigungu fishing village in the box

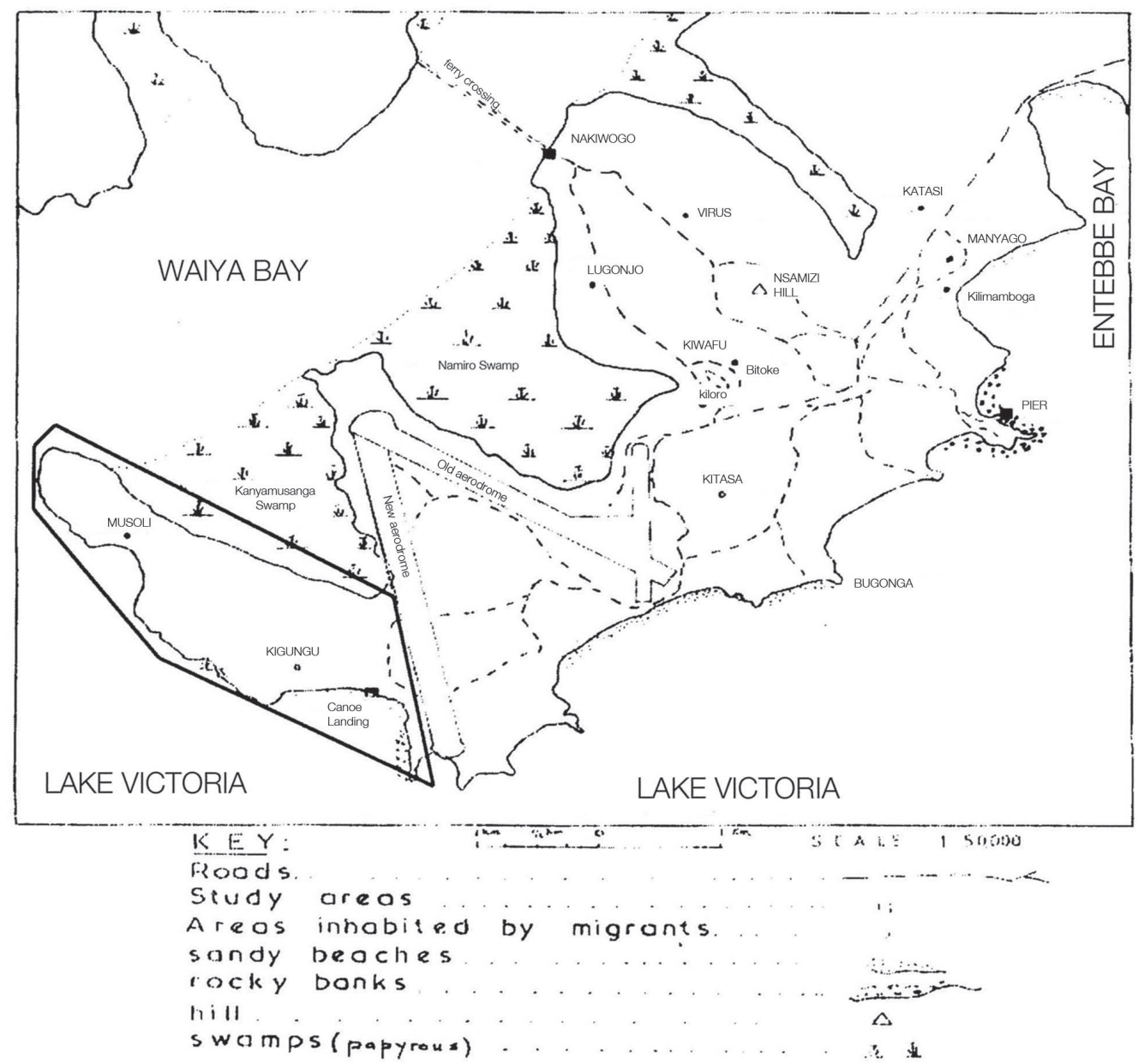

Figure 2

Map of Kigungu fishing village showing the areas of snails' collections.

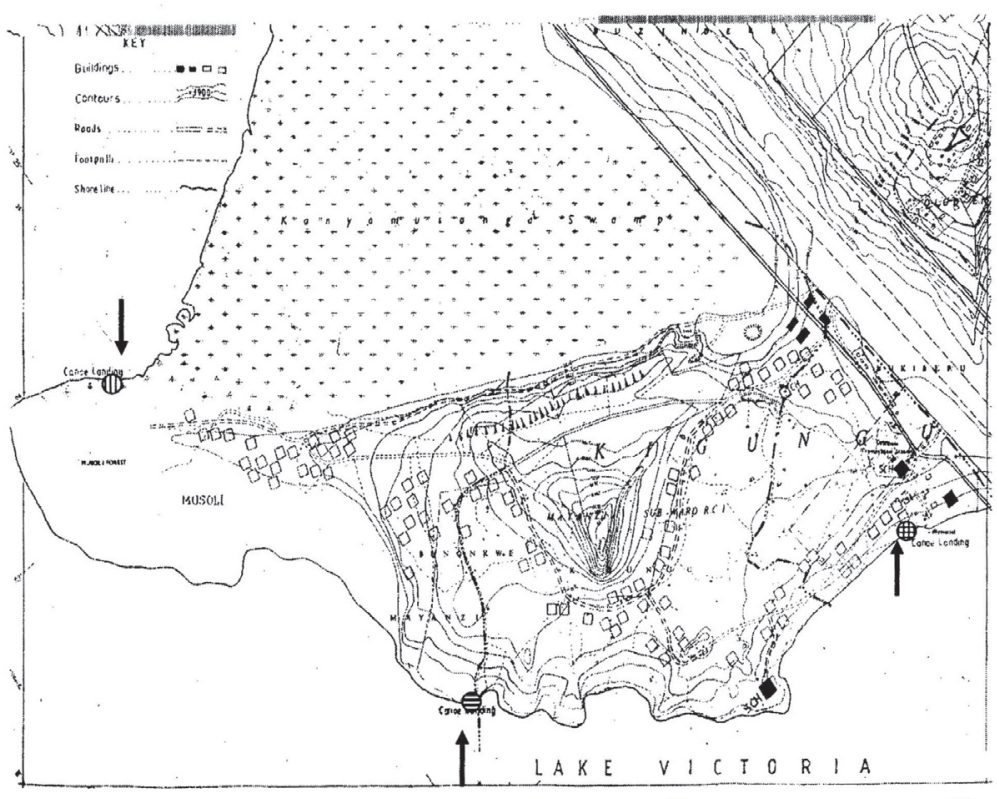

Arrows indicate, Kigungu Central $=$ 曹 $;$ Kigungu Mayanzi $=;$ Kigungu Misoli $=$ (IIIID

settlements $=\rightarrow$ Churches $=\square$ Wire less station and former East African Community buildings $=-$ 
Snail sampling was carried out once a week starting in January 2004 to December 2005. The accumulative total of the snails collected each month and subsequently in the year were recorded. The monthly rainfall data were obtained from the Meteorology Department in Entebbe. The snail sampling was carried out at Kigungu Central, Kigungu Misoli and Kigungu Mayanzi canoe landing and recreational sites where human water exposures are high. Standard methods for sampling the snails were used (5). Five standard dips were taken two meters apart in each site with a kitchen sieve scoop measuring $15 \mathrm{~cm}$ in diameter mounted on a two meter long wooden handle. The scoop was pushed through vegetation and the material collected was then washed gently by dabbing the bottom of the sieve on top of the lake water before the snails were picked out from the scoop using a pair of forceps into labelled polythene bags containing cotton wool dampened with water. Snails were sometimes hand picked from rocks and sandy beaches using a pair of long forceps. The samples were transported to Saint Jude Diagnostic Laboratory in Entebbe for species identification using the Danish Bilharzia Laboratory guidelines (5). Allintermediatehosts collected for each day were screened for the presence of cercariae by placing about 10-20 snails in 200 millilitres of filtered lake water in $100 \mathrm{ml}$ beakers.

The beakers were then exposed to natural bright sun light for three to four hours for cercaria shedding. The beakers containing cercariae were picked out and the snails in them placed singly in shedding test tubes with about 10-20 millilitres of filtered lake water and again exposed to natural bright sun light for further three to four hours. This was done to identify the cercariae shedding snails individually.

The total number of infected snails was then recorded and the shed cercariae were confirmed as human or non-human using identification keys described by DBL/WHO 1987 (5).

Data analysis: The monthly counts of different snail species were compared by one way analysis of variance (ANOVA) and correlation between pairs of snail density and rainfall were evaluated by Kendall Tau c.

\section{RESULTS}

The snails collection was carried out in all the three landing sites each day the exercise was performed. Because of very low collection in all the sites especially Kigungu Central with new settlements, the snails collected from the three sites were pooled together each day of collection. A total of 4630 B. choanomphala were collected in 2004 with a mean of 385.8 and a total of 2215 B. pfeifferi with a mean of 184.6 were also collected. There were 1790 B. tropicus that were collected in 2004 with a mean of 149 .2. Only 40 B. globosus were collected in the same period with a mean of 11.7 (Figure 3). In 2005, a total of 4452 B. choanomphala were collected with a mean of 371 and total of 1949 B. pfeifferi were also collected with a mean of 162.4. There were 1304 B. tropicus collected with a mean of 108.7. A total of 149 B. globosus with a mean of 14.4 were collected (Figure 4).

Figure 3

The effect of rainfall on the distribution of different intermediate host for schistosome in Kigungu fishing village in 2004

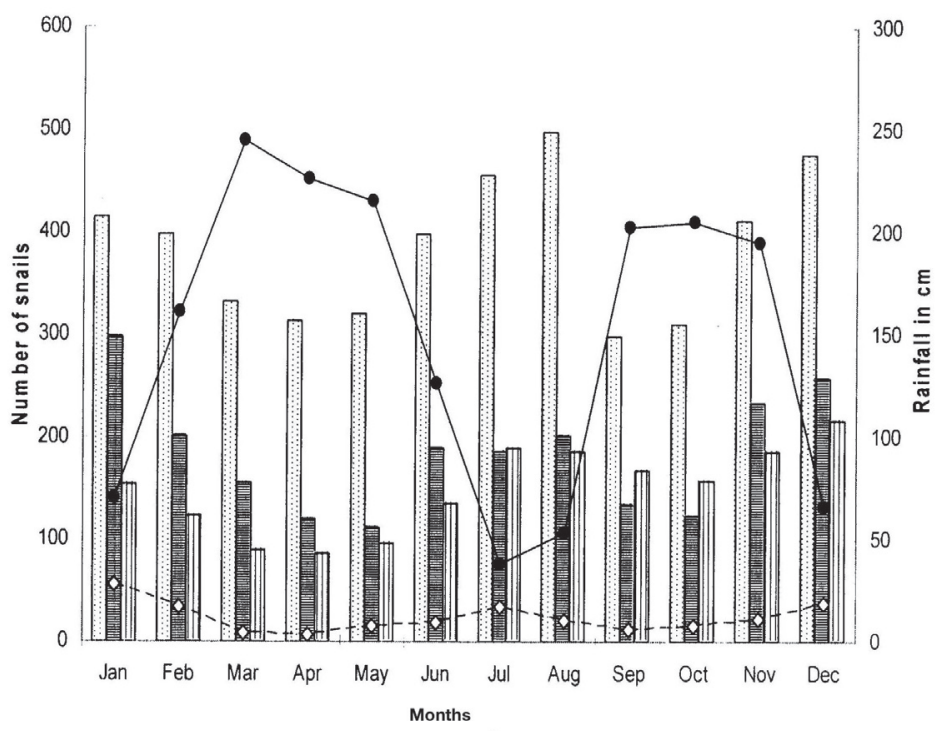

- = monthly rainfall; : = Biomphalaria $(B)$ choanomphala; 貝 $=$ Biompalaria pfeifferi; 四 $=$ Bulinus $(B)$ tropicus; $\diamond=$ Bulinus (B) globosus. 


\section{Figure 4}

The effect of rainfall on the distribution of different intermediate host for schistosome in Kigungu fishing village in 2005

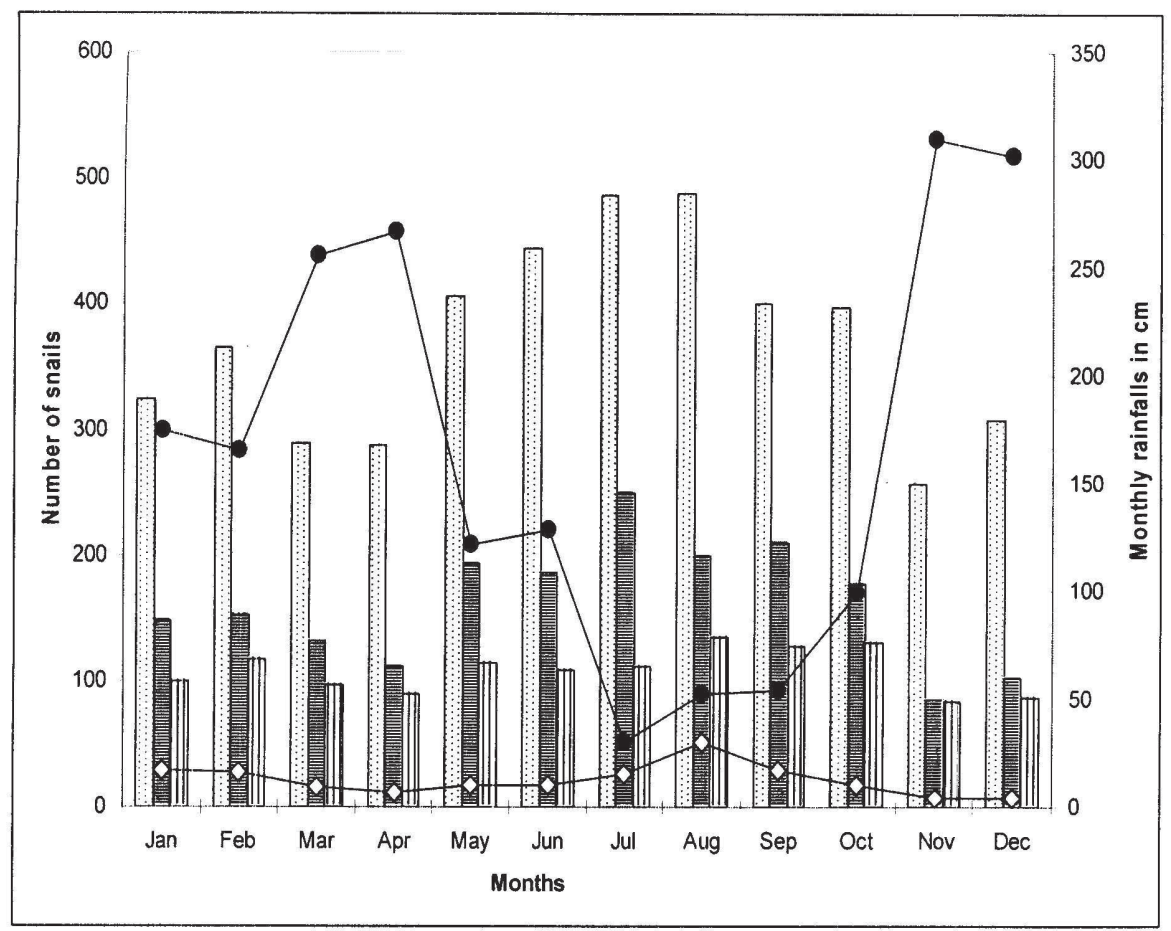

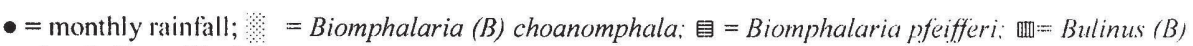
tropicus; $\diamond=$ Bulinus (B) globosus.

The population density of all snail species was inversely related to the rainfall pattern. B. choanomphala was the most prevalent followed by B. pfeifferi. Bulinus tropicus and B. globosus were rare. The mean rainfall in 2004 and 2005 was $150.25 \mathrm{~mm}$ and $163.3 \mathrm{~mm}$ respectively (Figure 4).

The snails collected in the two years were all screened for cercariae shedding. The numbers of different species of snails collected in the two years were similar as well as the rate of infected snails shedding cercariae. In 2004 and 2005, 1.7\% and 1.8\% B. choanomphala shed human cercariea and in the same years $1.9 \%$ and $1.7 \%$ B. pfeifferi shed human cercariae respectively. None of the Bulinus species shed human cercariae in both years (Table 1). The correlation between rainfall and snails population dynamic showed inverse significant $(\mathrm{P}=0.01)$ relationship with all the species of snails collected (Table 2).

Table 1

Intermediate hosts of schistosomes tested for cercariae shedding in 2004 and 2005

\begin{tabular}{lcccccc}
\hline Snails species & $\begin{array}{c}\text { Snails } \\
\text { collected }\end{array}$ & $\begin{array}{c}2004 \\
\text { Human } \\
\text { cercariae }\end{array}$ & $\begin{array}{c}{ }^{*} \text { Other } \\
\text { cercariae }\end{array}$ & $\begin{array}{c}\text { Snails } \\
\text { collected }\end{array}$ & $\begin{array}{c}2005 \\
\text { Human } \\
\text { cercariae }\end{array}$ & $\begin{array}{c}{ }^{*} \text { Other } \\
\text { cercariae }\end{array}$ \\
\hline B. choanomphala & 4742 & $82(1.7 \%)$ & $320(6.7 \%)$ & 4452 & $82(1.8 \%)$ & $302(6.8 \%)$ \\
B. pfeifferi & 2224 & $42(1.9 \%)$ & $246(11.1 \%)$ & 1949 & $33(1.7 \%)$ & $159(8.2 \%)$ \\
B. globosus & 140 & 0 & 0 & 152 & 0 & 0 \\
B. tropicus & 1790 & 0 & $37(2.1 \%)$ & 1304 & 0 & $30(2.3 \%)$ \\
\hline
\end{tabular}

\footnotetext{
* = non human cercariea no further identification was carried out.
} 
Table 2

Effect of rainfall on the snails' population dynamic (ANOVA) Spearman's correlations

\begin{tabular}{lllll}
\hline Rainfall vs. snail species & $\begin{array}{l}2004 \\
\text { Spearman's (r) }\end{array}$ & P-values & $\begin{array}{l}2005 \\
\text { Spearman's (r) }\end{array}$ & P-values \\
\hline Rainfall vs. B.choanomphala & -0.8231 & $<0.0016$ & -0.9091 & $<0.0001$ \\
Rainfall vs. B. pfeifferi & -0.6853 & $<0.0139$ & -0.9720 & $<0.0001$ \\
Rainfall vs. B. tropicus & -0.7832 & $<0.0026$ & -0.8601 & $<0.0003$ \\
Rainfall vs. B. globosus & -0.8070 & $<0.0015$ & -0.7492 & $<0.005$ \\
\hline
\end{tabular}

$\mathrm{r}=$ Spearman correlation measuring the relationship between snails density dynamic and annual rainfalls in both years. $\mathrm{P}=$ level of significance.

\section{DISCUSSION}

After about a decade since the presence of different intermediate hosts for S. mansoni was reported in Kigungu fishing village, many environmental changes have taken place in the area (11). Because of this, we re-examined the shoreline of the lake with emphasis on the three major landing sites at Kigungu central, Kigungu Mayanzi, and Misoli. The numbers of different species of snails collected in the two years were nearly the same and so was the number of snails, which shed the cercariae. This suggests even distribution of the snails along the shore with change in the rainfall.

The snails collected were screened for cercariae and B. choanomphala and B. pfeifferi shed human cercariae ill both years. Nevertheless the number of infected snails was low, B. choanomphala were more infected than B.pfeifferi and the difference between the infections in thetwoyearswas small(Table1). OdongoAginya demonstrated that among the indigenous snails collected from Entebbe at these landing sites, B. choanomphala was more susceptible than B. pfeifferi to infection with strains of $S$. mansoni brought from West Nile in the Northern part of Uganda (12).

Therefore, the higher rate of infection observed in B. choanomphala in this study confirmed better susceptibility to $S$. mansoni infection than B. pfeifferi $(8,13)$. The non-human cercariae shed by both $B$. choanomphala and B. pfeifferi were not identified. Bulinus globosus did not shed human cercariae or non-human cercariae but $B$. tropicus shed only nonhuman cercariae. The absence of human cercariae in Bulinus spp. in Kigungu landing sites showed that S. haematobium infection in this village is unlikely. This was shown by S. haematobium negative urine samples screened in previous studies in this village $(2,8,12)$. In spite of the environmental changes at the landing sites, this study found that the snails responsible for the transmission of $S$. mansoni in
Kigungu, B. choanomphala and B. pfeifferi are still present but in reduced number especially in areas where the papyrus swamp and sedges were cleared. Large numbers of B. pfeifferi, $\quad$ B. sudanica and Bulinus spp. were collected from these areas in the previous studies. The opened areas have attractive sandy beaches where the residents do most of their domestic and recreational activities. Beside the above water exposure activities, people from within and without Kigungu fishing village come to these landing sites to buy raw food, charcoal and firewood.

The permanent and semi-permanent settlements built along the shoreline are provided with cement concrete slaps at the lake side to serve as sand brake to the homes denying good habitats for the snails. The flash toilets and the water systems within these homes have reduced the water exposure frequency of these families. In addition to the safe water provided by these settlements, for the general community of Kigungu village, Entebbe municipal council has provided safe water to the areas in form of boreholes and communal tap water in the landing sites to reduce the frequent contact with the schistosome infested water. Further to the above, as part of health education to reduce contamination of the lakeshore with their excreta, the community was encouraged to build pit latrines and use them.

Besides, the residents were shown how to identify the intermediate hosts and the mode of $S$. mansoni transmission using the life cycle charts. Such knowledge is essential for those who live in endemic areas for regular monitoring of intermediate hosts in water contact sites (10). These types of environmental changes have been known to influence the distribution patterns and the population dynamics of the snails in permanent water bodies (5). Put together, the number of the snails that shed human cercaria in this study was still significant to course public health problem. This is because the residents of Kigungu are infected 
by getting in contact with the infested water in the transmission sites.

Similar observation was made elsewhere by Cridland (13) and Helmunt et al. (14). In this study, we found that in high rainfall the snails number reduced while in low rainfall and at the beginning of the rain the number of snails increased. That is the snails density is inversely related to the water levels. Others, Kabatereine et al. (16) and Gazinelli et al. (15) made similar observations. The months of January to February and May to October had low rainfall which progressed to dry seasons in some months. More snails were collected when the rainfall diminished than when there was much rain in both years (Figures 1 and 2). There was low rainfall in the first two months of 2005. Snail collection was high during this period but declined as the rainfall increased from March to early June. The peak of the snail collection in 2004 was in the months of July to August when the rainfall receded below $50 \mathrm{~mm}$. Snail populations decreased again with high rainfall in the months of September to November. This was finally followed by low rainfall and high snail density in the month of December. The pattern of rainfall and the snail density in 2004 were similar to that of 2005 except for the month of December 2004, which had excess rainfall and a reduced number of snails. More snails were collected during the dry seasons, at the beginning and the end of the rain season. The explanation to this phenomenon is that the snails are flashed out from the transmission sites by high velocity of the water as the snails cannot get attached to the water plants or rocks at the lakeshore (15). Changes in the rainfall pattern influenced snail distribution in many habitats and the overall population density pattern was found to be significantly correlated to the amount of rainfall in both years $(\mathrm{P}<0.0001)$. During high water level vegetation and floating objects at the lake are washed ashore and these have a direct relationship between snail habitats, rainfall and snail population density fluctuation in any given site.

Environmental modifications at the banks of water bodies aimed at reducing snail habitats are some of the ways of controlling the snails. Knowledge about the rainfall pattern and changes in snail density in endemic areas is essential in both snail and parasite intervention during control operations. That is, this knowledge helps in scheduling treatment regimens for successful chemotherapy control strategy. The recommended intervention period is usually one to two months after the infection is acquired during the low rainfall (17). Dissemination of knowledge about the intermediate hosts and their role in schistosomiasis transmission has increasingly become a good starting point for health education in the primary health care approach for disease control. This enables community participation in the surveillance of the snails at the transmission site and facilitates prompt reporting to the health authorities for action. Mollusciciding along the transmission sites at the end or just at the beginning of the raining seasons will reduce the snails' density as this kills most of the hatchlings and aestivating snails (17).

In conclusion, data from this study indicate that the snails responsible for the transmission of $S$. mansoni in Kigungu, B. choanomphala and B. pfeifferi are still present but in reduced number. And that focal mollusciciding and mass chemotherapy in this area could be done along the transmission sites at the beginning of the rain season which starts around January to February; May to July and December.

We recommend integrated approaches in the control of schistosomiasis mansoni in these landing sites. These include necessary health education, community awareness of intermediate host for schistosomiasis mansoni, their role in transmitting the parasite, continuation with environmental changes at the lake shore and mass chemotherapy in these transmission sites at the beginning of the rain season and possible control of these snails should accompany mollusciciding programmes to achieve an overall better control.

\section{ACKNOWLEDGEMENTS}

To the Ministry of Health, Uganda and Uganda Virus Research Institute for providing us with the logistics we needed for the study. We are equally grateful to the local councillors Messrs Poul Lukwago and the late Edward Sempala of Kigungu for their participation in this study by organising guides who lead our team to the snail collection sites along the lake. Messrs Richard Otheno (the late) and Pious Oswai in land and survey in Entebbe kindly provided maps of Entebbe and Kigungu respectively. The monthly and annual rainfalls were provided by George Obua Assistant Commissioner Meteorology Department Entebbe Uganda. We sincerely thank him for the useful data.

Finally, we are grateful to the technical staff of St. Jude diagnostic laboratory in Kitoro, Entebbe, Uganda for their assistance in collecting and processing the snails. This study received financial assistant from the European Union grant designation: SCHISTO-M-V AC (Uganda project component). 


\section{REFERENCES}

1. Kloos, H. and Thompson, K. Schistosomiasis in Africa: An ecological perspective. J. Trop. Geog. 1979; 48: $1-46$

2. Prentice, M.A., Panesar, T.S. and Coles. Transmission of Schistosoma munsoni in a large body of water. Ann. Trop. Med Parasitol. 1970; 64:339-348.

3. Jordan and Webbe, G. Schistosomiasis epidemiology, treatment and control. William Heinemann Medical Book Ltd, London. 1982.

4. Tropical Disease Control (TDR) and a Global Partnerships UNDP/WORLD BANK/WHO. Eight programme Report: The first ten years with highlight of the 1985-86 biennium.pp 49- 60 .

5. DBL/WHO. A basic field guide to the control of African human schistosomiasis. Second edition. WHO Collaborating Centre for Applied Medical Malacology and schistosomiasis ControI. 1987.

6. Geraerts, W.P.M., and Joose, J. Fresh water snails Basommatophora: The mollusca Ed. Wilbur, K. M., Academic press 1984.

7. Sturrock, R.F. The influence of temperature on the biology of Biomphalaria pfeifferi an intermediate host of Schistosoma mansoni. Ann. Trop. Med. Parasitol. 1996; 60: 100-105.

8. Odongo-Aginya, E.I., and Mugisha, C. The prevalence of Schistosoma mansoni in migrants from endemic areas living in the Entebbe Peninsula. East. Afr. Med. J. 1987; 9:571-579.

9. Kloos, H., de Souza Cecilia., Gazzinelli., et al. The distribution of biomphalaria, spp.in different habitats in relation to biological water contact and cognitive factors I rural areas in Minas Gerais, Brazil. Memo. Inst. Oswaldo Cruz. Rio de Jan. 96 and suppl. 2001; 57-66.

10. Chingwena, G., Mukaratirwa, S., Kristensen, T.K., et al. Trematodes infecting freshwater gastropods from the highveld and lowveld areas of Zimbabwe:
Proceedings of a Workshop on Medical and Veterinary Malacology in Africa Harare, Zimbabwe. November 8-12. 1999; pp 43-49.

11. Laamrani, H., Madsen, $\mathrm{H}$ and Boelee, E. Snail control in Africa: Towards a community-based environmental control. Proceeding of Workshop on Medical and Veterinary Malacology in Africa Harare, Zimbabwe. November 8-12. 1999; pp 183-192.

12. Odongo-Aginya, E.I. A Preliminary study on Intermediate snail hosts of schistosome in River Enyau Arua District, Uganda. East Afr.Med. J. 1992; 6:316-318.

13. Cridland, C.C. The experimental infection of several species of African fresh water snails with Schistosoma mansoni and Schistosolla haematobium. J. Trop. Med. Hyg. (A staple publication). 1955; 1-11.

14. Helmunt, K., Cecilia de Souza, Andrea, G., et al. The distribution of Biomphalaria spp.in different habitats in relation to physical, biological, water contact and cognitive factors in rural areas in Minas Gerais, Brazil. Memo. insl. Oswaldo Cruize Rio de J. 2001; 96, Suppl. 57-66.

15. Gazzinelli, A., Bethony, L. and Alves Fraga, I. Exposure to Schistosoma mansoni infection in rural Brazil. 1. Water contact. Trop. Med. Inter. Hlth. 2000; 6:126135.

16. Kabatereine, N.B., Kariuki, F., Kazibwe, F. et al. HSnail related aspects of transmission of Schistosoma mansoni at Butiaba, Lake Albert. North Western Uganda. Proceeding of Workshop on Medical and Veterinary Malacology in Africa Harare Zimbabwe. 1999; 141-154.

17. Meyer-Lassen. Study on Snails populations in the Rahad Agricultural Scheme, 'The Sudan with special emphasis on Bulinus truncates (audouini and Biomphalaria Pfeiffer (krauss) (Gastropoda: Planorbidae), snails intermediate host for species of the Genus Schistosoma. PhD thesis submitted to University of Copenhagen. 1992. 